\title{
Factors associated with length of stay in hospital for suspected community-acquired pneumonia
}

\author{
Jane Q Huang $\mathrm{MSc}^{1,2}$, Peter $\mathrm{M}$ Hooper $\mathrm{PhD}^{2}$, Thomas J Marrie MD ${ }^{1}$
}

JQ Huang, PM Hooper, TJ Marrie. Factors associated with length of stay in hospital for suspected community-acquired pneumonia. Can Respir J 2006;13(6):317-324.

OBJECTIVE: To determine factors associated with the length of stay (LOS) for patients with suspected community-acquired pneumonia (CAP) who required hospitalization for treatment.

STUDY DESIGN: The authors studied a population-based prospective cohort of 2757 adults with suspected CAP who were admitted over a two-year period. Logistic regression, multiple linear regression, and classification and regression trees were used to determine the factors associated with LOS.

SETTING: The study was conducted in two community and tertiary care hospitals, two community and secondary care hospitals, and two community hospitals in the Capital Health Region of Edmonton, Alberta.

RESULTS: Symptoms such as sweats, shaking chills and wheezing were associated with an LOS of seven days or shorter, whereas weight loss, functional impairment, heart, renal or neoplastic diseases and time to first dose of antibiotic were predictive of an LOS greater than seven days. Regression tree analysis indicated that rapid achievement of physiological stability was associated with a shorter LOS. The use of an indwelling urinary catheter was found to be an important determinant of LOS.

CONCLUSIONS: The present study found several new associations with increased LOS in patients with CAP, including functional status, time to receipt of first dose of antibiotic therapy, use of certain antibiotics, presence of a urinary catheter and the importance of time to physiological stability. An intervention targeting avoidance of urinary catheters may be associated with a shorter LOS.

\section{Les facteurs associés à la durée d'hospitalisation à la suite d'une présomption de pneumonie d'origine extra-hospitalière}

OBJECTIF : Déterminer les facteurs associés à la durée d'hospitalisation $(\mathrm{DH})$ des patients atteints d'une pneumonie d'origine extra-hospitalière (POEH) présumée devant être hospitalisés pour être traités.

CONCEPTION DE L'ÉTUDE : Les auteurs ont étudié une cohorte prospective en population de 2757 adultes atteints d'une POEH présumée, hospitalisés au cours d'une période de deux ans. La régression logistique, la régression linéaire multiple et les arbres de classification et de régression ont permis de déterminer les facteurs associés à la DH.

LIEU : L'étude a été menée dans deux hôpitaux généraux et tertiaires, deux hôpitaux généraux et secondaires et deux hôpitaux généraux de la région de la capitale d'Edmonton, en Alberta.

RÉSULTATS : Des symptômes comme la transpiration, les frissons et le wheezing s'associaient à une DH de sept jours ou moins, tandis que la perte de poids, l'atteinte fonctionnelle, une maladie cardiaque, rénale ou néoplastique et le délai avant la première dose d'antibiotiques étaient prédictifs d'une DH de plus de sept jours. D'après l'analyse des arbres de régression, l'obtention rapide d'une stabilité physiologique favorisait une réduction de la $\mathrm{DH}$. Le recours à une sonde urinaire à demeure constituait un important déterminant de la DH.

CONCLUSIONS : La présente étude a permis d'observer plusieurs nouvelles associations à une augmentation de la $\mathrm{DH}$ chez les patients atteints d'une POEH, y compris l'état fonctionnel, le délai avant la première dose de l'antibiothérapie, l'utilisation de certains antibiotiques, la présence d'un cathéter urinaire et l'importance du délai avant la stabilité physiologique. Une intervention visant à éviter les cathéters urinaires pourrait favoriser une réduction de la $\mathrm{DH}$.

Key Words: Community-acquired; Length of stay; Pneumonia

Community-acquired pneumonia (CAP) is a common illUness in Canada, with an annual incidence of 12 cases per 1000 adults per year, in which approximately $15 \%$ of cases require admission to a hospital for treatment $(1,2)$. Pneumonia is the infectious disease with the highest health care costs $(3,4)$. In Alberta, CAP results in an annual hospitalization rate of four cases per 1000 adults and accounts for 8500 annual hospital discharges at a cost of more than $\$ 40$ million per year (5). The association between severity of illness and the length of stay (LOS) in hospital is clearly established for CAP (6). However, LOS is influenced by various other factors, such as clinicians' practice style, availability of beds, and the availability of social services such as long-term care facilities for placement of those who can no longer care for themselves (7). It is evident that the major cost factor in CAP is hospitalization, and LOS is a major driver of that cost. A better understanding of the factors influencing hospital stay should lead to measures to reduce LOS.
The objective of the present study was to determine factors associated with LOS for patients admitted with suspected CAP in the Capital Heath Region of Edmonton, Alberta.

\section{Study population}

\section{PATIENTS AND METHODS}

A pneumonia pathway, consisting of components for managing pneumonia with or without hospital admission, was implemented over the period from November 15, 2000, to November 14, 2002, at six hospitals and one free-standing emergency room in Edmonton. Six research nurses were hired to assist in implementing the pathway and collecting data. These nurses had no role in the delivery of care to patients with CAP.

The pathway consisted of an admission guideline (8), preprinted orders covering routine aspects of care, and an algorithm for administration and discontinuation of supplemental oxygen and antimicrobial therapy (levofloxacin orally or cefuroxime plus 
azithromycin intravenously were the options provided); however, other options were not prohibited. Reminders to medical staff regarding assessment of vaccination status for pneumococcal and influenza vaccines were provided, and a recommendation for administration of these vaccines, if indicated, was included on the order sheet. In addition, counselling and literature regarding cessation of smoking were made available to tobacco smokers. A three-part discharge algorithm was part of the pathway. Once the patients had achieved physiological stability (9), as defined by an oral temperature of $37.5^{\circ} \mathrm{C}$ or less for $24 \mathrm{~h}$, a respiratory rate of 24 breaths/min or less for $24 \mathrm{~h}$, an oxygen saturation of $90 \%$ or greater while breathing room air or a return to baseline saturation levels, and the ability to eat and drink enough to maintain hydration, functional (get-up-and-go test [10] and an assessment of activities of daily living if the patient failed the get-up-and-go test) and mini-mental status assessments were carried out $(8,10,11)$. In general, functional status and mental status assessments were performed only on those patients who were 65 years of age or older. Functional status before admission was categorized as walking independently, walking with assistance and walking with a prosthesis; wheelchair or bed-bound status was also recorded.

Adult patients (older than 17 years) were enrolled in the pathway if they presented to the emergency department, at one of the seven institutions in the Capital Health Region, with two or more symptoms or signs of CAP, plus radiographic evidence of pneumonia as interpreted by the emergency room physician or internal medicine consultant. Symptoms and signs of CAP included cough (productive or nonproductive), pleuritic chest pain, shortness of breath, temperature higher than $38^{\circ} \mathrm{C}$, and crackles or bronchial breathing on auscultation.

Patients were excluded from the pathway if they required admission to an intensive care unit from the emergency room, or if they were thought to have aspiration pneumonitis (defined as pulmonary opacities in the presence of recent loss of consciousness, vomiting or observation of respiratory distress within $30 \mathrm{~min}$ of feeding), tuberculosis or cystic fibrosis. Pregnant and nursing mothers, as well as immunosuppressed patients (those who were using more than $10 \mathrm{mg}$ of prednisone per day or other immunosuppressive drugs), were also excluded. Those with HIV infection were excluded if their $\mathrm{CD}_{4}$ count was less than $0.25 \times 10^{9} / \mathrm{L}$. During the second year of the study, patients with aspiration pneumonia were included in the pathway.

Cases selected for the present study were admitted patients who were enrolled in the pathway. Patients who died during hospitalization, who had multiple visits or whose LOS was longer than 30 days were excluded from analysis. Finally, those whose records were missing the date of presentation to the emergency room or a date of discharge were also excluded.

Definite CAP patients were those who had a chest radiograph interpreted by a radiologist as pneumonia.

\section{Statistical analysis}

The analyses were performed using SPSS version 12.0 (SPSS Inc, USA) and SAS version 8.2 (SAS Inc, USA). Descriptive statistics and the differences between means and proportions were tested using Student's $t$ test, $F$ test or $\chi^{2}$ test.

Because the median LOS was 6.4 days, patients who stayed longer than seven days were compared with those who stayed seven days or less. The response variable LOS was treated in two ways: as a binary variable (LOS longer than seven days and LOS seven days or less); and as a continuous variable (days from emergency room presentation to discharge). When the response variable was treated as a binary variable, logistic regression $(12,13)$ and a classification tree $(14,15)$ were used to predict whether the LOS would exceed seven days. When the response variable was treated as a continuous variable, multiple linear regression and a regression tree $(14,15)$ were used to determine the factors associated with the LOS. The variables with $\mathrm{P}<0.1$ in the univariate analysis were used in the logistic regression model, multiple linear regression model, and classification and regression trees (CARTs).

Multiple linear regression was also used to determine the factors associated with LOS in the patients with definite CAP.

The logistic regression analysis was performed using SPSS version 12.0. Backward selection with an entry probability of 0.05 and a removal probability of 0.1 was used to select the final model. The Hosmer and Lemeshow goodness-of-fit test was used to evaluate the adequacy of the logistic regression models.

CARTs were estimated using SAS Enterprise Miner 4.0 (SAS Inc). The data set was divided into training (75\%) and validation (25\%) data. A $\chi^{2}$ with a significance level of 0.2 was set as the splitting criterion for the classification tree, and an F test with a significance level of 0.2 was set as the splitting criterion for the regression tree. The minimum number of observations in a leaf was 10 . The observations required for a split search was 50 . The maximum number of branches from a node was two. The maximum depth of a tree was 10. Missing values were treated as acceptable values. The best classification rate (proportion correctly classified) was used as a model assessment measure for the classification tree, and the average square error was used as a model assessment measure for the regression tree. The subtree that produced the best results according to the selected model assessment measure was chosen (ie, the tree with the highest classification rate among the classification trees or the tree with the smallest average square error among the regression trees was selected). A Kass adjustment (P value multiplied by a Bonferroni factor dependent on the number of branches) was applied before choosing the number of branches, and a Bonferroni factor was applied to the tree node before the split was selected; therefore, the split was adjusted based on an adjusted $\mathrm{P}$ value. The Kass adjustment may have caused the $\mathrm{P}$ value to become less significant. Depth adjustment was also applied (ie, a Bonferroni adjustment for the number of leaves to correct excessive rejections).

Proc DMREG (data mining regression procedure) (SAS 8.2, SAS Inc) was used to develop a multiple linear regression model. The data set was divided into training (50\%), validation (25\%) and test $(25 \%)$ data. The training data set was used to fit the initial model, the validation data set was used to compute assessment statistics and to fine tune the model during stepwise selection, and the test data set was used to compute assessment statistics. The model option was defined as follows: the model type was linear; the link function was the identity function; the input coding was generalized linear modelling; and an intercept was included in the model. The stepwise model selection method was used, and the significance level for entry and stay was 0.05 . The model selection criterion was Schwarz's Bayesian criterion.

\section{RESULTS}

A total of 3474 patients with pneumonia were admitted during the two years of the study. Seven hundred seventeen $(20.6 \%)$ patients were excluded from the study. The reasons for exclusion were as follows: 301 (42.0\%) died; 162 (22.6\%) had multiple visits; 168 (23.4\%) stayed longer than 30 days; and 86 (12.0\%) had missing admission or discharge dates. Thus, 2757 patients $(79.4 \%$ of the total inpatient group) were included in the analysis. 
TABLE 1

Demographic characteristics of the study group according to hospital length of stay (LOS)

\begin{tabular}{|c|c|c|c|c|}
\hline & Overall & $\begin{array}{c}\text { LOS } \\
\leq 7 \text { days }\end{array}$ & $\begin{array}{c}\text { LOS } \\
>7 \text { days }\end{array}$ & $\mathbf{P}$ \\
\hline Age, mean years $\pm S D$ & $68.3 \pm 17.8$ & $65.7 \pm 18.7$ & $71.9 \pm 15.9$ & $<0.001$ \\
\hline Total patients & 2757 & 1603 & 1154 & 0.007 \\
\hline Male, $n(\%)$ & $1426(51.7)$ & $864(53.9)$ & $562(48.7)$ & \\
\hline Study site ${ }^{*}, \mathrm{n}(\%)$ & 2757 & 1603 & 1154 & $<0.001$ \\
\hline Site A & 548 (19.9) & $331(20.6)$ & $217(18.8)$ & \\
\hline Site B & $969(35.1)$ & $497(31.0)$ & $472(40.9)$ & \\
\hline Site C & $392(14.2)$ & $220(13.7)$ & $172(14.9)$ & \\
\hline Site D & $373(13.5)$ & $239(14.9)$ & $134(11.6)$ & \\
\hline Site $\mathrm{E}$ & $157(5.7)$ & $109(6.8)$ & $48(4.2)$ & \\
\hline Site F & $318(11.5)$ & $207(12.9)$ & $111(9.6)$ & \\
\hline CAP pathway used, n (\%) & 2730 & 1585 & 1145 & 0.008 \\
\hline Yes & $1025(37.5)$ & $621(39.2)$ & $404(35.3)$ & \\
\hline Partially used & $1307(47.9)$ & $719(45.4)$ & $588(51.4)$ & \\
\hline No & $398(14.6)$ & $245(15.5)$ & $153(13.4)$ & \\
\hline Smoking history, n (\%) & 2456 & 1431 & 1025 & 0.010 \\
\hline Nonsmoker & $808(32.9)$ & $474(33.1)$ & $334(32.6)$ & \\
\hline Smoker & $694(28.3)$ & $433(30.3)$ & $261(25.5)$ & \\
\hline Ex-smoker & $954(38.8)$ & $524(36.6)$ & $430(42.0)$ & \\
\hline $\begin{array}{l}\text { Residence on } \\
\text { admission, } \mathrm{n}(\%)\end{array}$ & 2744 & 1592 & 1152 & $<0.001$ \\
\hline Home & $1776(64.7)$ & $1116(70.1)$ & $660(57.3)$ & \\
\hline Homecare & $415(15.1)$ & $187(11.7)$ & $228(19.8)$ & \\
\hline Lodge/group home & $240(8.7)$ & $127(8.0)$ & $113(9.8)$ & \\
\hline $\begin{array}{l}\text { Subacute/continuing } \\
\text { care facility }\end{array}$ & $245(8.9)$ & $117(7.3)$ & $128(11.1)$ & \\
\hline Shelter/jail/homeless & $68(2.5)$ & $45(2.8)$ & $23(2.0)$ & \\
\hline $\begin{array}{l}\text { Weight loss }>5 \% \text { of } \\
\text { body weight, } n(\%)\end{array}$ & 2402 & 1394 & 1008 & $<0.001$ \\
\hline Yes & $195(8.1)$ & $76(5.5)$ & $119(11.8)$ & \\
\hline Functional status, n (\%) & 2655 & 1551 & 1104 & $<0.001$ \\
\hline Walking with no problems & $1710(64.4)$ & $1108(71.4)$ & $602(54.5)$ & \\
\hline $\begin{array}{l}\text { Walking with assistance } \\
\text { (cane, walker, person- } \\
\text { assisted) }\end{array}$ & $708(26.7)$ & $332(21.4)$ & $376(34.1)$ & \\
\hline Prosthesis & $8(0.3)$ & $2(0.1)$ & $6(0.5)$ & \\
\hline Bedridden & $67(2.5)$ & $35(2.3)$ & $32(2.9)$ & \\
\hline Wheelchair-bound & $162(6.1)$ & $74(4.8)$ & $88(8.0)$ & \\
\hline $\begin{array}{l}\text { Mean hours from presenting } \\
\text { to } E R \text { to first antibiotic }(n=26\end{array}$ & $\begin{array}{l}8.3 \pm 13.5 \\
698)\end{array}$ & $7.0 \pm 7.2$ & $10.2 \pm 18.9$ & $<0.001$ \\
\hline
\end{tabular}

* Sites $A$ and $B$ are community and tertiary care hospitals, sites $C$ and $D$ are community and secondary care hospitals, and sites $E$ and $F$ are community hospitals. CAP Community-acquired pneumonia; ER Emergency room

The mean age of the study group was $68.3 \pm 17.8$ years, $1426(51.7 \%$ ) were male, $32.9 \%$ ( 808 of 2456 ) were nonsmokers, 28.3\% (694 of 2456) were current smokers and the rest were ex-smokers. The majority $(64.7 \%)$ were admitted from home with no home care, and $15.1 \%$ were admitted from a residence where they required some care. One thousand four hundred forty-seven $(53.8 \%)$ were confirmed as having pneumonia by a radiologist (ie, definite CAP). The mean LOS was $8.3 \pm 6.3$ days, and the median LOS was 6.4 days.

Tables 1 and 2 compare those who stayed seven days or less with those who stayed longer than seven days. Older age, ex-smoker status, home care, reduced premorbid functional status and longer time to first dose of antibiotic were all associated with a longer stay. In contrast, male sex, pathway use,
TABLE 2

Symptoms, signs and comorbidities of patients with a hospital length of stay (LOS) of seven days or less compared with those who stayed more than seven days

\begin{tabular}{|c|c|c|c|c|}
\hline & Overall & $\begin{array}{c}\text { LOS } \\
\leq 7 \text { days }\end{array}$ & $\begin{array}{c}\text { LOS } \\
>7 \text { days }\end{array}$ & $\mathbf{P}$ \\
\hline Temperature, ${ }^{\circ} \mathrm{C}(\mathrm{n}=2718)^{*}$ & $37.5 \pm 1.1$ & $37.5 \pm 1.1$ & $37.3 \pm 1.1$ & $<0.001$ \\
\hline $\begin{array}{l}\text { Respiratory rate, } \\
\text { breaths } / \mathrm{min}(\mathrm{n}=2669)^{*}\end{array}$ & $26 \pm 7.7$ & $25.6 \pm 7.4$ & $26.5 \pm 7.9$ & 0.002 \\
\hline $\begin{array}{l}\text { Oxygen saturation on room } \\
\text { air, } \%(n=1648)^{*}\end{array}$ & $89.6 \pm 7.0$ & $90.1 \pm 6.2$ & $88.6 \pm 8.0$ & $<0.001$ \\
\hline Temperature, n (\%) & 2718 & 1581 & 1137 & 0.038 \\
\hline $35.5^{\circ} \mathrm{C}$ to $38^{\circ} \mathrm{C}$ & $1831(67.4)$ & $1040(65.8)$ & $791(69.6)$ & \\
\hline$<35.5^{\circ} \mathrm{C}$ or $>38^{\circ} \mathrm{C}$ & $887(32.6)$ & $541(34.2)$ & $346(30.4)$ & \\
\hline Respiratory rate, $\mathrm{n}(\%)$ & 2669 & 1551 & 1118 & 0.014 \\
\hline 16 to 24 breaths $/ \mathrm{min}$ & $1518(56.9)$ & $913(58.9)$ & $605(54.1)$ & \\
\hline$<16$ or $>24$ breaths $/ \mathrm{min}$ & $1151(43.1)$ & $638(41.1)$ & $513(45.9)$ & \\
\hline $\begin{array}{l}\text { Oxygen saturation on } \\
\text { room air, } \mathrm{n}(\%)\end{array}$ & 1648 & 1031 & 617 & 0.001 \\
\hline$<90 \%$ & $677(41.1)$ & $392(38.0)$ & $285(46.2)$ & \\
\hline$\geq 90 \%$ & $971(58.9)$ & $639(62.0)$ & $332(53.8)$ & \\
\hline \multicolumn{5}{|l|}{ Symptom, n (\%) } \\
\hline Sweats & $260(9.4)$ & $182(11.4)$ & $78(6.8)$ & $<0.001$ \\
\hline Fever & $1285(46.6)$ & $801(50.0)$ & $484(41.9)$ & $<0.001$ \\
\hline Shaking chills & $649(23.5)$ & $438(27.3)$ & $211(18.3)$ & $<0.001$ \\
\hline Chest pain & $620(22.5)$ & $382(23.8)$ & $238(20.6)$ & 0.047 \\
\hline Cough & $2056(74.6)$ & $1239(77.3)$ & $817(70.8)$ & $<0.001$ \\
\hline Sputum production & $1356(49.2)$ & $834(52.0)$ & $522(45.2)$ & $<0.001$ \\
\hline Altered mental state & $317(11.5)$ & $155(9.7)$ & $162(14.0)$ & $<0.001$ \\
\hline Pleuritic chest pain & $303(11.0)$ & $194(12.1)$ & $109(9.4)$ & 0.028 \\
\hline Wheeze & $604(21.9)$ & $380(23.7)$ & $224(19.4)$ & 0.007 \\
\hline Crackles on auscultation & $1003(36.4)$ & $554(34.6)$ & $449(38.9)$ & 0.019 \\
\hline \multicolumn{5}{|l|}{ Comorbidity, n (\%) } \\
\hline Asthma & $389(14.1)$ & $249(15.5)$ & $140(12.1)$ & 0.011 \\
\hline COPD & $895(32.5)$ & $494(30.8)$ & $401(34.7)$ & 0.030 \\
\hline Diabetes, insulin-dependent & $158(5.7)$ & $80(5.0)$ & $78(6.8)$ & 0.049 \\
\hline Heart disease & $1209(43.9)$ & $642(40.0)$ & $567(49.1)$ & $<0.001$ \\
\hline Cancer & $356(12.9)$ & $190(11.9)$ & $166(14.4)$ & 0.050 \\
\hline Dementia & $177(6.4)$ & $84(5.2)$ & $93(8.1)$ & 0.003 \\
\hline Psychiatric disorder & $356(12.9)$ & $185(11.5)$ & $171(14.8)$ & 0.011 \\
\hline Stroke & $290(10.5)$ & $137(8.5)$ & $153(13.3)$ & $<0.001$ \\
\hline \multicolumn{5}{|c|}{ Comorbidity using PORT criteria, $\mathrm{n}(\%)^{\dagger}$} \\
\hline Neoplastic disease & $199(7.2)$ & $95(5.9)$ & $104(9.0)$ & 0.002 \\
\hline Liver disease & $85(3.1)$ & $59(3.7)$ & $26(2.3)$ & 0.032 \\
\hline Cerebrovascular disease & $212(7.7)$ & $100(6.2)$ & $112(9.7)$ & 0.001 \\
\hline Congestive heart failure & $461(16.7)$ & $223(13.9)$ & $238(20.6)$ & $<0.001$ \\
\hline Renal disease & $339(12.3)$ & $157(9.8)$ & $182(15.8)$ & $<0.001$ \\
\hline None of the above & $1644(59.6)$ & $1056(65.9)$ & $588(51.0)$ & $<0.001$ \\
\hline
\end{tabular}

${ }^{*}$ Data are presented as means $\pm S D$; ${ }^{\dagger}$ See reference 6. COPD Chronic obstructive pulmonary disease; PORT Pneumonia Patient Outcomes Research Team

residence at home without home care, and shorter time to receipt of first dose of antibiotic were associated with a shorter stay. LOS was also site dependent.

Patients who stayed seven days or less were more likely to have a higher temperature; to complain of fever, sweats, shaking chills, chest pain, cough, sputum production and pleuritic chest pain; and to have wheezes on examination of the chest. They were also more likely to have a lower respiratory rate and higher oxygen saturation while breathing room air. Those who stayed longer than seven days were more likely to have altered mental status and to have a variety of comorbidities. 
TABLE 3

Multivariate analysis of factors predicting a hospital length of stay longer than seven days in patients with suspected community-acquired pneumonia

\begin{tabular}{|c|c|c|}
\hline & $\mathbf{P}$ & OR $(95 \% \mathrm{CI})$ \\
\hline Site* & $<0.001$ & \\
\hline Site $A$ versus site $D$ & 0.026 & 1.40 (1.04 to 1.89$)$ \\
\hline Site $B$ versus site $D$ & $<0.001$ & 1.96 (1.47 to 2.61$)$ \\
\hline Site $C$ versus site $D$ & 0.005 & $1.68(1.17$ to 2.41$)$ \\
\hline Site $E$ versus site $D$ & 0.796 & $0.95(0.62$ to 1.45$)$ \\
\hline Site $F$ versus site $D$ & 0.396 & $1.17(0.81$ to 1.68$)$ \\
\hline Weight loss $>5 \%$ of body weight & $<0.001$ & 1.94 (1.40 to 2.69$)$ \\
\hline Functional status & $<0.001$ & \\
\hline $\begin{array}{l}\text { Walking with assistance versus } \\
\text { walking independently }\end{array}$ & $<0.001$ & 1.87 (1.52 to 2.31$)$ \\
\hline $\begin{array}{l}\text { Prosthesis versus walking } \\
\text { independently }\end{array}$ & 0.388 & $2.16(0.38$ to 12.45$)$ \\
\hline Bedridden versus walking independently & 0.009 & 2.09 (1.20 to 3.63$)$ \\
\hline $\begin{array}{l}\text { Wheelchair-bound versus walking } \\
\text { independently }\end{array}$ & 0.001 & $1.84(1.27$ to 2.65$)$ \\
\hline Sweats & 0.011 & $0.67(0.50$ to 0.91$)$ \\
\hline Shaking chills & 0.006 & $0.74(0.60$ to 0.92$)$ \\
\hline Wheeze & 0.007 & $0.74(0.60$ to 0.92$)$ \\
\hline Heart disease & 0.026 & $1.23(1.02$ to 1.47$)$ \\
\hline Renal disease & 0.015 & $1.38(1.06$ to 1.78$)$ \\
\hline Neoplastic disease & 0.041 & $1.43(1.02$ to 2.00$)$ \\
\hline Hours antibiotic given within & 0.036 & \\
\hline $4 \mathrm{~h}$ to $8 \mathrm{~h}$ versus $\leq 4 \mathrm{~h}$ & 0.886 & $0.98(0.80$ to 1.21$)$ \\
\hline$>8 \mathrm{~h}$ versus $\leq 4 \mathrm{~h}$ & 0.027 & $1.28(1.03$ to 1.59$)$ \\
\hline Constant & $<0.001$ & 0.35 \\
\hline
\end{tabular}

* Sites $A$ and $B$ are community and tertiary care hospitals, sites $C$ and $D$ are community and secondary care hospitals, and site $E$ and $F$ are community hospitals
Ten factors were significantly associated with an LOS longer than seven days on logistic regression analysis (Table 3). When other factors were fixed, patients who had sweats, shaking chills and wheeze stayed seven days or less (ORs of 0.67, 0.74 and 0.74, respectively). Patients who were walking with assistance, bedridden or using a wheelchair stayed longer than seven days more often than those who walked independently (ORs of 1.87, 2.09 and 1.84, respectively). Patients who had weight loss, heart disease, renal disease, neoplastic disease or who waited longer to receive the first dose of antibiotic stayed longer than seven days more often (ORs of 1.94, 1.23, 1.38, 1.43 and 1.28, respectively).

The classification tree yielded a tree model with five leaves (Figure 1). After applying the classification rule to all data, the classification rate was $62 \%$. Indeed, five factors - walking with difficulty, any comorbidity, no liver disease, no sputum production and no shaking chills - were key in predicting an LOS longer than seven days.

Because the distribution of LOS is positively skewed, the natural logarithm of LOS (Ln[LOS]) was used as the response variable in multiple linear regression and the regression tree. To determine the factors associated with $\mathrm{Ln}(\mathrm{LOS})$ in multiple linear regression, demographic characteristics, symptoms, medical history, antibiotic use and in-hospital complications were used in the analysis. Fifteen variables were associated with Ln(LOS) (Table 4).

The median LOS of patients who had weight loss or who walked with assistance was 1.29 times that of patients who did not. The median LOS of patients who were treated with ciprofloxacin, cefuroxime, clindamycin or metronidazole was longer than that of patients who did not receive these antibiotics. If the patients had an indwelling urinary catheter or empyema, they tended to stay longer in hospital. Patients who had heart disease, shortness of breath, altered mental state or chronic obstructive pulmonary disease stayed longer in hospital

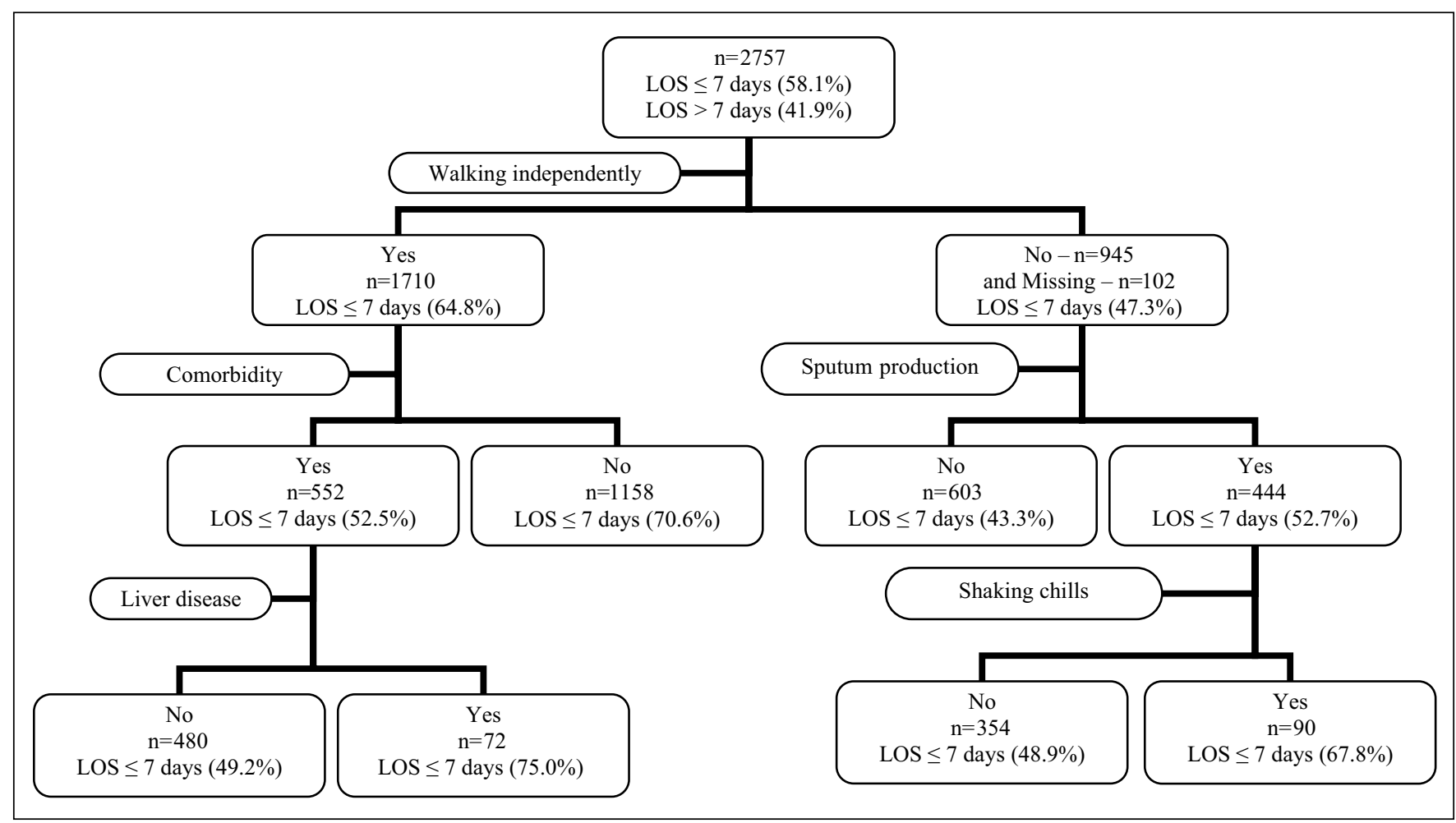

Figure 1) Classification tree for predicting a length of stay (LOS) in hospital longer than seven days or an LOS of seven days or shorter 


\begin{tabular}{|c|c|c|}
\hline & $\mathbf{P}$ & Ratio* $(95 \% \mathrm{Cl})$ \\
\hline \multicolumn{3}{|l|}{ Site $^{\dagger}$} \\
\hline Site $A$ versus site $D$ & 0.007 & $1.21(1.05$ to 1.38$)$ \\
\hline Site $B$ versus site $D$ & 0.563 & $0.96(0.84$ to 1.10$)$ \\
\hline Site $C$ versus site $D$ & 0.470 & 1.07 (0.90 to 1.27$)$ \\
\hline Site $E$ versus site $D$ & 0.084 & 0.84 (0.68 to 1.02$)$ \\
\hline Site $F$ versus site $D$ & 0.033 & $0.83(0.70$ to 0.98$)$ \\
\hline \multicolumn{3}{|l|}{ Functional status } \\
\hline $\begin{array}{l}\text { Walking with assistance versus } \\
\text { walking independently }\end{array}$ & $<0.001$ & $1.29(1.17$ to 1.43$)$ \\
\hline Prosthesis versus walking independently & 0.760 & $1.16(0.45$ to 3.00$)$ \\
\hline Bedridden versus walking independently & 0.143 & 1.24 (0.93 to 1.64$)$ \\
\hline $\begin{array}{l}\text { Wheelchair-bound versus walking } \\
\text { independently }\end{array}$ & 0.779 & $1.03(0.86$ to 1.23$)$ \\
\hline $\begin{array}{l}\text { Weight loss }>5 \% \text { of body weight } \\
\text { (yes versus no) }\end{array}$ & 0.001 & $1.29(1.12$ to 1.48$)$ \\
\hline Heart disease (yes versus no) & 0.002 & $1.14(1.05$ to 1.25$)$ \\
\hline $\begin{array}{l}\text { Indwelling urinary catheter (new) } \\
\text { (yes versus no) }\end{array}$ & $<0.001$ & $1.29(1.15$ to 1.45$)$ \\
\hline Empyema (yes versus no) & $<0.001$ & 2.47 (1.78 to 3.42$)$ \\
\hline Liver disease (yes versus no) & 0.006 & $0.73(0.59$ to 0.91$)$ \\
\hline COPD (yes versus no) & 0.002 & 1.15 (1.06 to 1.26$)$ \\
\hline Altered mental state (yes versus no) & 0.009 & $1.20(1.05$ to 1.37$)$ \\
\hline Shortness of breath (yes versus no) & $<0.001$ & $1.18(1.08$ to 1.30$)$ \\
\hline Cefuroxime (used versus not used) & 0.001 & $1.19(1.07$ to 1.32$)$ \\
\hline Ciprofloxacin (used versus not used) & 0.001 & $1.42(1.15$ to 1.74$)$ \\
\hline Clindamycin (used versus not used) & $<0.001$ & $1.39(1.17$ to 1.64$)$ \\
\hline Metronidazole (used versus not used) & 0.001 & 1.31 (1.13 to 1.53$)$ \\
\hline $\begin{array}{l}\text { Hours from presenting to ER to first dose } \\
\text { of antibiotic (per additional hour) }\end{array}$ & $<0.001$ & $1.01(1.0$ to 1.01$)$ \\
\hline
\end{tabular}

*Ratio of two median LOS (for example, the ratio of median LOS of site $B$ to median LOS of site $D$ is 0.96); ' Sites $A$ and $B$ are community and tertiary care hospitals, sites $C$ and $D$ are community and secondary care hospitals, and sites $E$ and $F$ are community hospitals. COPD Chronic obstructive pulmonary disease; ER Emergency room

than those who did not. A longer time to first dose of antibiotic also contributed to a longer median LOS. Patients who had liver disease tended to have a shorter LOS in hospital.

Table 5 lists the 10 factors associated with $\operatorname{Ln}(\mathrm{LOS})$ for the definite CAP patients. Patients who had in-hospital complications such as indwelling urinary catheter, respiratory failure requiring mechanical ventilation, empyema, new-onset diabetes mellitus and new-onset hypokalemia stayed longer in hospital. The median LOS of patients who were treated with clindamycin or metronidazole was longer than that of patients who did not receive these antibiotics. Older age, longer time to first dose of antibiotic and weight loss all contributed to a longer median LOS.

The regression tree had 15 leaves (Figure 2). From the tree, it can be seen that the time to be able to eat and drink well enough to maintain hydration is an important determinant of LOS. Patients who were able to eat and drink well enough to maintain hydration in three days had a shorter LOS than those who could not reach this milestone. Use of an indwelling urinary catheter is another important determinant of LOS; patients who had an indwelling urinary catheter tended to stay longer in hospital than those who did not. For patients who were not able to eat and
TABLE 5

Multiple linear regression analysis of factors associated with the median length of stay (LOS) of definite pneumonia patients

\begin{tabular}{|c|c|c|}
\hline & $\mathbf{P}$ & Ratio* $(95 \% \mathrm{Cl})$ \\
\hline Age (per additional year) & $<0.001$ & 1.01 (1.01 to 1.02 ) \\
\hline Clindamycin (used versus not used) & 0.006 & 1.36 (1.09 to 1.68$)$ \\
\hline Metronidazole (used versus not used) & 0.002 & 1.41 (1.13 to 1.75$)$ \\
\hline $\begin{array}{l}\text { Indwelling urinary catheter (new) } \\
\text { (yes versus no) }\end{array}$ & 0.001 & 1.35 (1.14 to 1.61$)$ \\
\hline $\begin{array}{l}\text { Respiratory failure requiring mechanical } \\
\text { ventilation (yes versus no) }\end{array}$ & 0.009 & 1.97 (1.19 to 3.26$)$ \\
\hline Empyema (yes versus no) & 0.001 & 2.33 (1.39 to 3.91$)$ \\
\hline New-onset diabetes mellitus (yes versus no) & $<0.001$ & 2.62 (1.59 to 4.30$)$ \\
\hline $\begin{array}{l}\text { New-onset hypokalemia } \\
\quad \text { (potassium }<3 \mathrm{mmol} / \mathrm{L} \text { ) (yes versus no) }\end{array}$ & 0.008 & 3.55 (1.41 to 8.96$)$ \\
\hline $\begin{array}{l}\text { Weight loss }>5 \% \text { of body weight } \\
\text { (yes versus no) }\end{array}$ & 0.001 & 1.40 (1.16 to 1.70$)$ \\
\hline $\begin{array}{l}\text { Hours from presenting to ER to first dose } \\
\text { of antibiotic (per additional hour) }\end{array}$ & 0.003 & 1.01 (1.00 to 1.01$)$ \\
\hline
\end{tabular}

*Ratio of two median LOS (for example, the ratio of median LOS of using clindamycin to median LOS of not using clindamycin is 1.36). ER Emergency room

drink well enough to maintain hydration in three days, and who did not have an indwelling urinary catheter, functional status was another factor associated with LOS. Patients who walked independently stayed in hospital for a shorter time than those who walked with assistance. For patients who were able to eat and drink well enough to maintain hydration in three days and had an indwelling urinary catheter, antibiotic therapy within $12 \mathrm{~h}$ was associated with a shorter LOS. For patients who were able to eat and drink well enough to maintain hydration in three days, and who did not have an indwelling urinary catheter, site of care, having had a comorbidity, not achieving an oxygen saturation level of $90 \%$ or greater in five days were all associated with a longer LOS. Table 6 lists the factors that were associated with LOS in a logistic regression model for all suspected pneumonia patients and in multiple linear regression models for all suspected and definite pneumonia patients. Weight loss and time of first administration of antibiotics were included in all three models; this suggests that these may be important factors associated with LOS.

\section{DISCUSSION}

LOS for patients with CAP has been the subject of intense investigation over the past few decades. Previous studies (16-34) show that a large number of factors influence LOS. Low socioeconomic status predicted a 5.9 days longer LOS in one study (32). In other studies, patients with CAP cared for by hospitalists had a shorter LOS than those seen by primary care physicians (25), and patients cared for by subspecialists practicing within their subspeciality had a shorter LOS than those cared for by subspecialists practicing outside their subspeciality (19). In one study, variation in clinician behaviour accounted for $13 \%$ of the variability in LOS (20). In another study, early mobilization of patients with CAP led to a reduction in LOS: 6.9 days for those who received the usual mobilization versus 5.8 days for those who received early mobilization (23). These studies usually examined one factor in isolation.

In an administrative database study (24) of all patients with CAP admitted to hospital over a five-year period in the province of Alberta, increasing age, comorbidity, admission to 


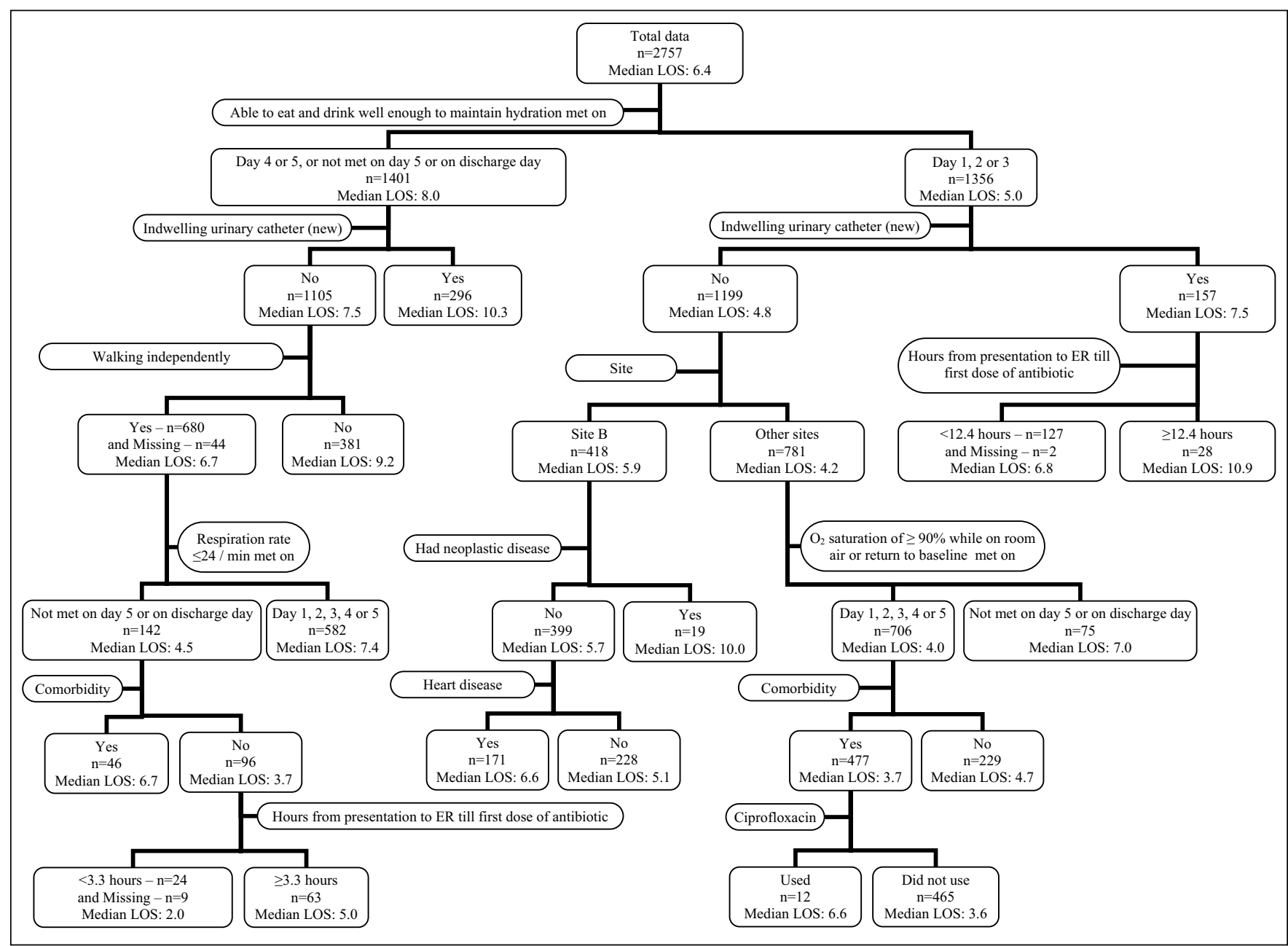

Figure 2) Regression tree of analysis of factors predicting hospital length of stay (LOS) in patients with suspected community-acquired pneumonia. ER Emergency room; Site B Community and tertiary care hospital

a regional or urban hospital (versus a rural one), special care unit admission, mechanical ventilation for more than $96 \mathrm{~h}$, respiratory failure, hypotension, female sex and requirement for in-hospital dialysis were all associated with a longer LOS. While administrative data allow one to capture all patients with a disease, the data are unfortunately limited to a few items, and the accuracy of diagnosis is often an issue.

The administration of antibiotics within $4 \mathrm{~h}$ of arrival at the emergency department has been associated with a shorter LOS, as has been the type of antibiotic administered $(18,27,33)$.

Our prospective study of all patients who had a clinical diagnosis of pneumonia and who were admitted to hospital for treatment in a large Canadian city allowed us to take a more comprehensive approach to determining the factors associated with LOS in patients with CAP. We used a variety of analytical techniques to elucidate the factors associated with LOS. In addition to confirming many of the previous factors associated with LOS, we have shown that many others are also associated with increased LOS. Our results are consistent with those cited above - site of care, older age, functional status and increased time to first dose of antibiotic were all associated with increased LOS in our multivariate analysis. Our data add to the list of factors impacting LOS (16-34).

Functional status has been known to be a predictor of both in-hospital and long-term mortality from CAP (35-38).
In the present study, we found that walking independently was associated with a shorter LOS than walking with assistance.

The use of either ciprofloxacin, cefuroxime, metronidazole or clindamycin was associated with increased LOS. In a multicentre, multinational study of 844 patients with bacteremic pneumococcal pneumonia, Yu et al (39) noted that therapy with cefuroxime was associated with higher mortality when the penicillin minimum inhibitory concentration was increased. We have now shown that it is associated with a longer LOS. Diarrhea (including Clostridium difficile-associated diarrhea) is an adverse effect of clindamycin, which is frequently used to treat aspiration pneumonia $(40,41)$. Therefore, there are at least two reasons for the association of clindamycin and increased LOS. Metronidazole is frequently used to treat $\mathrm{C}$ difficileassociated diarrhea. Ciprofloxacin is often used to treat infection due to a variety of Gram-negative bacteria. It is likely that this antibiotic was used to treat patients in whom secondary infection was suspected or confirmed. Our recommendations for antibiotic therapy were levofloxacin orally or cefuroxime plus erythromycin intravenously. There were 25 patients in the present study who were treated with cefuroxime only; the mean LOS for this group was $8.5 \pm 7.1$ days.

Most instructive, however, were the results of the regression tree analysis. CARTs are used to predict membership of cases or objects in the classes of a categorical dependent variable 
from their measurements on one or more predictor variables. CARTs can deal with incomplete data and multiple types of features both in input features and predicted features; moreover, the trees produce interpretable rules (14).

Time to physiological stability was very important at a variety of levels in the regression tree. In a study of 688 adults hospitalized with CAP, Halm et al (9) found that the median time to stability was three days using a lenient definition and seven days using a conservative definition. Our definition of physiological stability is given in the Methods section. It is noteworthy that three of the four factors - ability to eat and drink, oxygen saturation and respiratory rate less than 24 breaths/min were important in determining LOS. In another study, Halm et al (42) noted that patients discharged with two or more instabilities had a fivefold greater risk of death or readmission.

The requirement for a urinary catheter was an important factor in LOS in the regression tree. Urinary tract infections account for $40 \%$ of all nosocomial infections, and the majority of these are in patients with indewelling urinary catheters (43). These infections result in increased mortality and LOS (44). Avoidance of urinary catheters in patients with CAP is a testable strategy that may lead to a reduction in the LOS for this group of patients.

In some studies, introducing pathways of care has resulted in a reduction in $\operatorname{LOS}(2,28)$. However, in a seven-site, clusterrandomized clinical trial involving 325 control and 283 intervention patients, Fine et al (22), using a guideline for discharge similar to ours, were unable to show a reduction in LOS, although fewer patients in the intervention arm had complications.

The strengths of our study are that we enrolled every patient with pneumonia over a two-year period. The prospective, observational nature of the study allowed us to collect a lot of data that are missing from administrative databases.

The limitations of the study are that it was conducted in one geographic area of Canada, and the results may not be generalizable to other countries or even to the rest of Canada. Our definition of pneumonia, which relied on the attending physician's interpretation of the chest radiograph as pneumonia, may be considered a limitation by some. However, the interobserver variability of radiologists in the radiographic diagnosis of pneumonia is at least 20\% (45) and, furthermore, these patients were admitted for pneumonia and did not have a change in diagnosis during hospital stay. Moreover, we also analyzed patients with definite pneumonia separately.

In the present study, we have used several statistical techniques to investigate factors related to LOS in CAP patients. This kind of investigation is inherently difficult, and the results should be interpreted with caution. Commenting on CARTs, Hastie et al (46) wrote, "One major problem with trees is their high variance. Often a small change in the data can result in a very different series of splits, making interpretation somewhat precarious". Similar considerations apply to variable selection methods in multiple linear regression; for example, Ramsey and Shafer (47) advised, "The explanatory variables chosen are not necessarily special. Inclusion of individual explanatory variables is affected strongly by the correlations between them". Given the limitations of each approach, we have chosen to report the results of several substantially different analyses. If a variable is included in several models, then that suggests somewhat stronger evidence that the variable is relevant.
TABLE 6

\begin{tabular}{|c|c|c|c|}
\hline \multirow[b]{2}{*}{ Pneumonia patient } & \multirow{2}{*}{$\begin{array}{c}\begin{array}{c}\text { Logistic } \\
\text { regression }\end{array} \\
\text { All suspected }\end{array}$} & \multicolumn{2}{|c|}{$\begin{array}{l}\text { Multiple linear } \\
\text { regression }\end{array}$} \\
\hline & & All suspected & Definite \\
\hline Age & No & No & Yes \\
\hline Site & Yes & Yes & No \\
\hline Functional status & Yes & Yes & No \\
\hline Weight loss $>5 \%$ of body weight & Yes & Yes & Yes \\
\hline $\begin{array}{l}\text { Hours from presenting to ER to } \\
\text { first dose of antibiotic }\end{array}$ & Yes & Yes & Yes \\
\hline \multicolumn{4}{|l|}{ Symptom } \\
\hline Sweats & Yes & No & No \\
\hline Shaking chills & Yes & No & No \\
\hline Wheeze & Yes & No & No \\
\hline Altered mental state & No & Yes & No \\
\hline Shortness of breath & No & Yes & No \\
\hline \multicolumn{4}{|l|}{ Comorbidity } \\
\hline Heart disease & Yes & Yes & No \\
\hline Renal disease & Yes & No & No \\
\hline Neoplastic disease & Yes & No & No \\
\hline Liver disease & No & Yes & No \\
\hline COPD & No & Yes & No \\
\hline Complication & Not used & & \\
\hline $\begin{array}{l}\text { Indwelling urinary } \\
\text { catheter (new) }\end{array}$ & & Yes & Yes \\
\hline Empyema & & Yes & Yes \\
\hline $\begin{array}{l}\text { Respiratory failure requiring } \\
\text { mechanical ventilation }\end{array}$ & & No & Yes \\
\hline New-onset diabetes mellitus & & No & Yes \\
\hline $\begin{array}{l}\text { New-onset hypokalemia } \\
\quad \text { (value of potassium }<3 \mathrm{mmol} / \mathrm{L} \text { ) }\end{array}$ & & No & Yes \\
\hline Antibiotic & Not used & & \\
\hline Clindamycin & & Yes & Yes \\
\hline Metronidazole & & Yes & Yes \\
\hline Cefuroxime & & Yes & No \\
\hline Ciprofloxacin & & Yes & No \\
\hline
\end{tabular}

COPD Chronic obstructive pulmonary disease; ER Emergency room

\section{CONCLUSIONS}

We have confirmed many of the previous associations with increased LOS, including age - and we have added several new ones, including functional status, home care, time to receipt of first dose of antibiotic, use of certain antibiotics, presence of a urinary catheter and time to physiological stability.

ACKNOWLEDGEMENTS: This study was funded by an independent research establishment grant from the Alberta Heritage Foundation for Medical Research, and by grants-in-aid from Capital Health, Abbott Canada, Pfizer Canada and JannsenOrtho Inc, Canada. We thank the following CAP pathway nurses: JoAnne de Jager, Linda Gardner, Lynne Korobanik, Tammy Pfeiffer, Cynthia Proskow, Sue Marshall, Nancy Baker, Nan Horne and Fredrika Herbert. The staff of EPICORE carried out data management for the project.

FINANCIAL DISCLOSURE: Dr Marrie, in addition to the above funding, has served on an advisory board for Abbott Canada, and has grants for other studies from Bristol-Myers Squibb Canada and Bayer Canada. 


\section{REFERENCES}

1. Feagan BG, Marrie TJ, Lau CY, Wheeler SL, Wong CJ, Vandervoort MK. Treatment and outcomes of community-acquired pneumonia at Canadian hospitals. CMAJ 2000;162:1415-20.

2. Marrie TJ, Lau CY, Wheeler SL, Wong CJ, Vandervoort MK, Feagan BG. A controlled trial of a critical pathway for treatment of community-acquired pneumonia. CAPITAL Study Investigators. Community-Acquired Pneumonia Intervention Trial Assessing Levofloxacin. JAMA 2000;283:749-55.

3. Monge V, Gonzalez A. Hospital admissions for pneumonia in Spain. Infection 2001;29:3-6.

4. Monge V, San-Martin VM, Gonzalez A. The burden of communityacquired pneumonia in Spain. Eur J Public Health 2001;11:362-4.

5. Carriere KC, Jin Y, Marrie TJ, Predy G, Johnson DH. Outcomes and costs among seniors requiring hospitalization for community-acquired pneumonia in Alberta. J Am Geriatr Soc 2004;52:31-8.

6. Fine MJ, Auble TE, Yealy DM, et al. A prediction rule to identify low-risk patients with community-acquired pneumonia. N Engl J Med 1997;336:243-50.

7. Burns LR, Wholey DR. The effects of patient, hospital, and physician characteristics on length of stay and mortality. Med Care 1991;29:251-71.

8. Marrie TJ, Michalyk D, Man P, et al. A critical pathway for treating community-acquired pneumonia. Can J Contin Med Educ 2001;13:43-59.

9. Halm EA, Fine MJ, Marrie TJ, et al. Time to clinical stability in patients hospitalized with community-acquired pneumonia: Implications for practice guidelines. JAMA 1998;279:1452-7.

10. Podsiadlo D, Richardson S. The timed "Up \& Go": A test of basic functional mobility for frail elderly persons. J Am Geriatr Soc 1991;39:142-8.

11. Crum RM, Anthony JC, Bassett SS, Folstein MF. Population-based norms for the Mini-Mental State Examination by age and educational level. JAMA 1993;269:2386-91.

12. Agresti A. An Introduction to Categorical Data Analysis. New York: John Wiley and Sons Inc, 1996.

13. Hosmer DW, Lemeshow S. Applied Logistic Regression. New York: John Wiley and Sons Inc, 1989.

14. Breiman L, Friedman JH, Olshen RA, Stone CJ. Classification and Regression Trees. Monterey: Wadsworth Inc, 1984.

15. Yohannes Y, Hoddinott J. Classification and Regression Trees: An Introduction. Technical Guide \#3. Washington, DC: International Food Policy Research Institute, 1999.

16. Masotti L, Ceccarelli E, Cappelli R Barabesi L, Guerrini M, Forconi S. Length of hospitalization in elderly patients with communityacquired pneumonia. Aging (Milano) 2000;12:35-41.

17. Ewig S, Seifert K, Kleinfeld T, Goke N, Schafer H. Management of patients with community-acquired pneumonia in a primary care hospital: A critical evaluation. Respir Med 2000;94:556-63.

18. Houck PM, Bratzler DW, Nsa W, Ma A, Bartlett JG. Timing of antibiotic administration and outcomes for Medicare patients hospitalized with community-acquired pneumonia. Arch Intern Med 2004;164:637-44.

19. Weingarten SR, Lloyd L, Chiou CF, Braunstein GD. Do subspecialists working outside of their specialty provide less efficient and lowerquality care to hospitalized patients than do primary care physicians? Arch Intern Med 2002;162:527-32.

20. Laing R, Coles C, Chambers S, et al. Community-acquired pneumonia: Influence of management practices on length of hospital stay. Intern Med J 2004;34:91-7.

21. Menendez R, Cremades MJ, Martinez-Moragon E, Soler JJ, Reyes S, Perpina M. Duration of length of stay in pneumonia: Influence of clinical factors and hospital type. Eur Respir J 2003;22:643-8.

22. Fine MJ, Stone RA, Lave JR, et al. Implementation of an evidencebased guideline to reduce duration of intravenous antibiotic therapy and length of stay for patients hospitalized with community-acquired pneumonia: A randomized controlled trial. Am J Med 2003;115:343-51.

23. Mundy LM, Leet TL, Darst K, Schnitzler MA, Dunagan WC. Early mobilization of patients hospitalized with community-acquired pneumonia. Chest 2003;124:883-9.

24. Jin Y, Marrie TJ, Carriere KC, et al. Variation in management of community-acquired pneumonia requiring admission to Alberta, Canada hospitals. Epidemiol Infect 2003;130:41-51.
25. Rifkin WD, Conner D, Silver A, Eichorn A. Comparison of processes and outcomes of pneumonia care between hospitalists and communitybased primary care physicians. Mayo Clin Proc 2002;77:1053-8.

26. Menendez R, Ferrando D, Valles JM, Vallterra J. Influence of deviation from guidelines on the outcome of community-acquired pneumonia. Chest 2002;122:612-7.

27. Battleman DS, Callahan M, Thaler HT. Rapid antibiotic delivery and appropriate antibiotic selection reduce length of hospital stay of patients with community-acquired pneumonia: Link between quality of care and resource utilization. Arch Intern Med 2002;162:682-8.

28. Meehan TP, Weingarten SR, Holmboe ES, et al. A statewide initiative to improve the care of hospitalized pneumonia patients: The Connecticut Pneumonia Pathway Project. Am J Med 2001;111:203-10.

29. Menendez R, Ferrando D, Valles JM, Martinez E, Perpina M. Initial risk class and length of hospital stay in community-acquired pneumonia. Eur Respir J 2001;18:151-6.

30. Fine MJ, Pratt HM, Obrosky DS, et al. Relation between length of hospital stay and costs of care for patients with community-acquired pneumonia. Am J Med 2000;109:378-85.

31. Benenson R, Magalski A, Cavanaugh S, Williams E. Effects of a pneumonia clinical pathway on time to antibiotic treatment, length of stay, and mortality. Acad Emerg Med 1999;6:1243-8.

32. Stelianides S, Golmard JL, Carbon C, Fantin B. Influence of socioeconomic status on features and outcome of communityacquired pneumonia. Eur J Clin Microbiol Infect Dis 1999;18:704-8.

33. Stahl JE, Barza M, DesJardin J, Martin R, Echman MH. Effect of macrolides as part of initial empiric therapy on length of stay in patients hospitalized with community-acquired pneumonia. Arch Intern Med 1999;159:2576-80.

34. McCormick D, Fine MJ, Coley CM, et al. Variation in length of hospital stay in patients with community-acquired pneumonia: Are shorter stays associated with worse medical outcomes? Am J Med 1999;107:5-12.

35. Riquelme R, Torres A, El-Ebiary M, et al. Community-acquired pneumonia in the elderly: A multivariate analysis of risk and prognostic factors. Am J Respir Crit Care Med 1996;154:1450-5.

36. Oga T, Nishimura K, Tsukino M, Sato S, Hajiro T. Analysis of the factors related to mortality in chronic obstructive pulmonary disease: Role of exercise capacity and health status. Am J Respir Crit Care Med 2003;167:544-9.

37. Davis RB, Iezzoni LI, Phillips RS, Reiley P, Coffman GA, Saffran C. Predicting in-hospital mortality. The importance of functional status information. Med Care 1995;33:906-21.

38. Salive ME, Satterfield S, Ostfeld AM, Wallace RB, Havlik RJ. Disability and cognitive impairment are risk factors for pneumoniarelated mortality in older adults. Public Health Rep 1993;108:314-22.

39. Yu VL, Chiou CC, Feldman C, et al; International Pneumococcal Study Group. An international prospective study of pneumococcal bacteremia: Correlation with in vitro resistance, antibiotics administered, and clinical outcome. Clin Infect Dis 2003;37:230-7.

40. Fekety R, Silva J, Browne RA, Rifkin GD, Ebright JR. Clindamycininduced colitis. Am J Clin Nutr 1979;32:244-50.

41. Shek FW, Stacey BS, Rendell J, Hellier MD, Hanson PJ. The rise of Clostridium difficile: The effect of length of stay, patient age and antibiotic use. J Hosp Infect 2000;45:235-7.

42. Halm EA, Fine MJ, Kapoor WN, Singer DE, Marrie TJ, Siu AL. Instability on hospital discharge and the risk of adverse outcomes in patients with pneumonia. Arch Intern Med 2002;162:1278-84.

43. Kalsi J, Arya M, Wilson P, Mundy A. Hospital-acquired urinary tract infection. Int J Clin Pract 2003;57:388-91.

44. Kunin CM. Nosocomial urinary tract infections and the indwelling catheter: What is new and what is true? Chest 2001;120:10-2.

45. Young M, Marrie TJ. Interobserver variability in the interpretation of chest roentgenograms of patients with possible pneumonia. Arch Intern Med 1994;154:2729-32.

46. Hastie T, Tibshirani R, Friedman JH. The Elements of Statistical Learning: Data Mining, Inference, and Prediction. New York: Springer-Verlag, 2001:274.

47. Ramsey FL, Shafer DW. The Statistical Sleuth: A Course in Methods of Data Analysis, 2nd edn. Pacific Grove: Duxbury, 2002:346. 


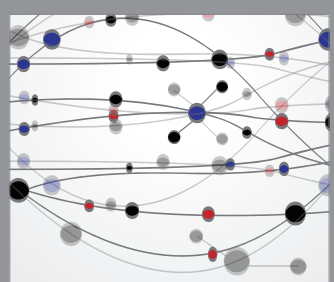

The Scientific World Journal
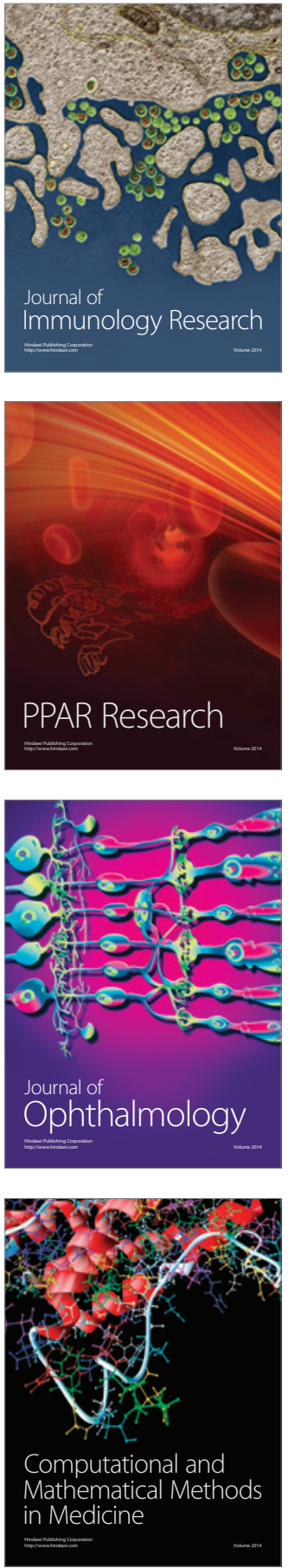

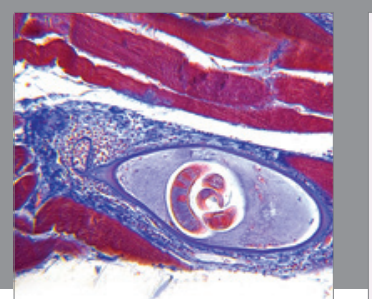

Gastroenterology Research and Practice

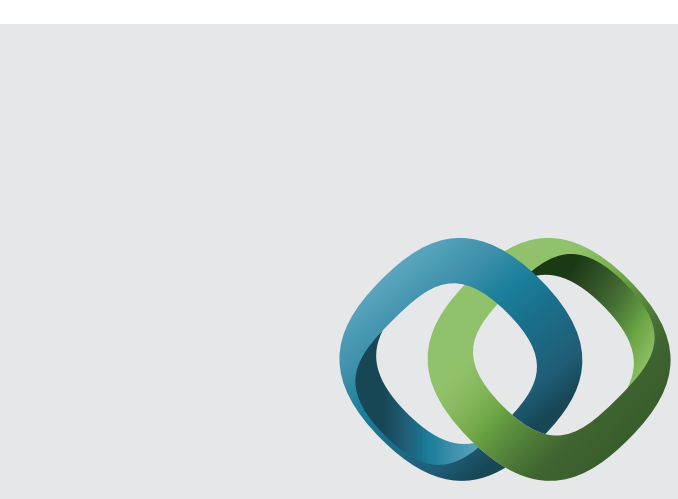

\section{Hindawi}

Submit your manuscripts at

http://www.hindawi.com
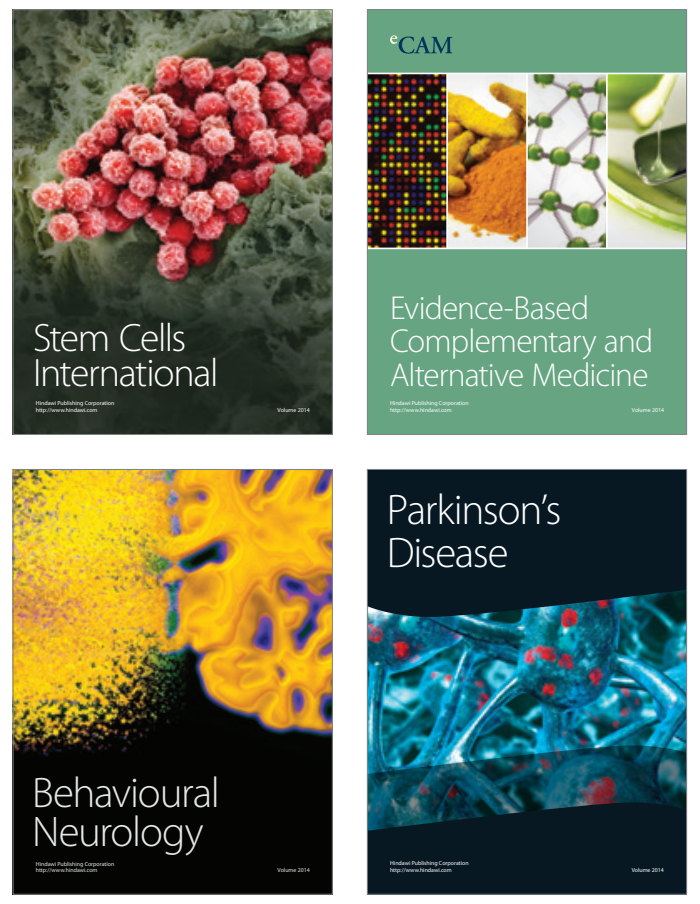
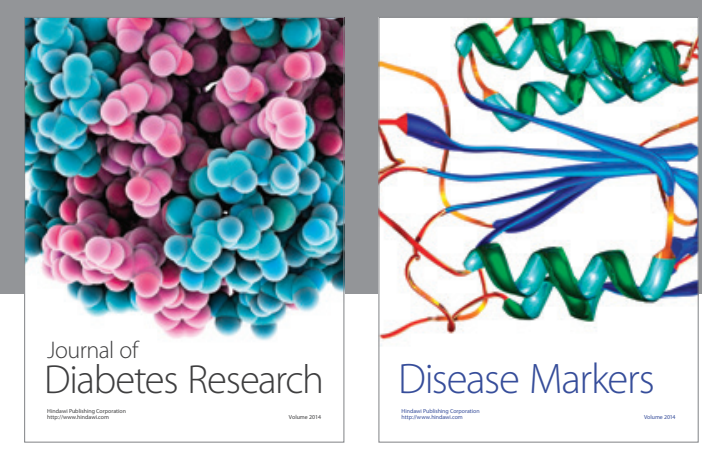

Disease Markers
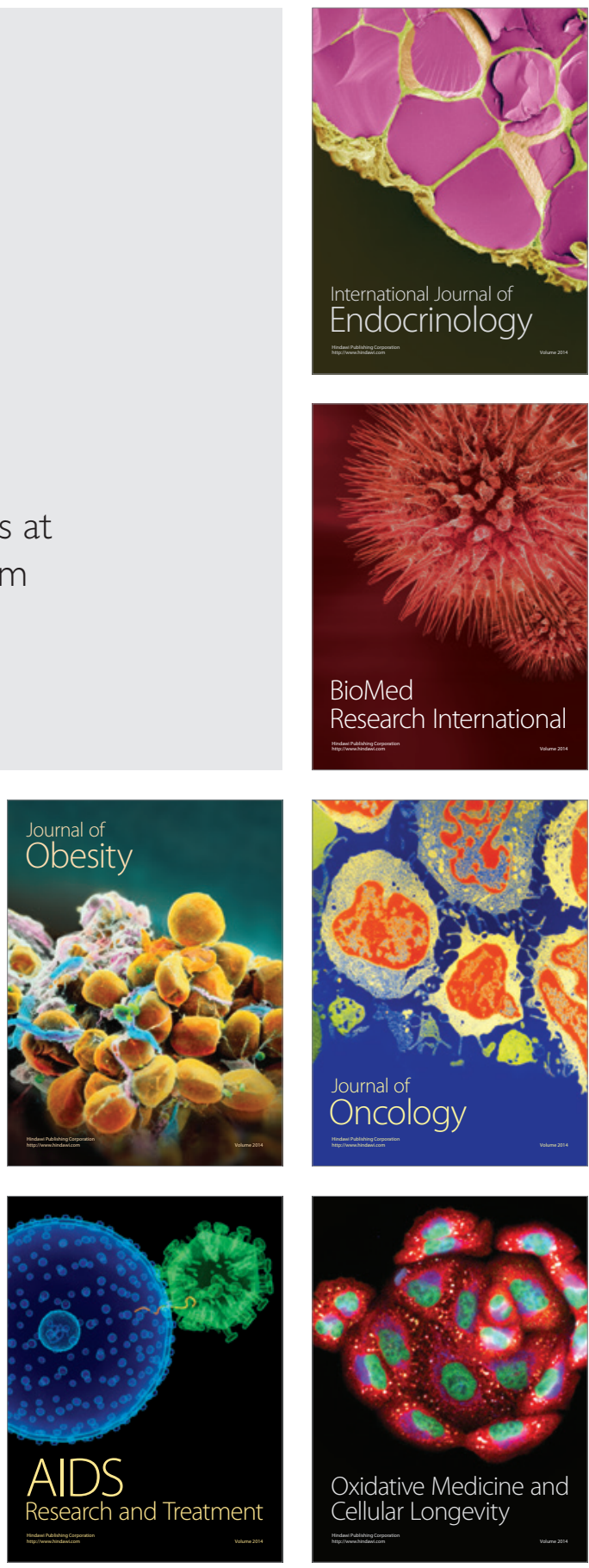